\title{
Roll-bond condenser in a two-phase thermosyphon loop for power electronics cooling
}

\author{
F. Agostini \& T. Gradinger \\ Corporate Research, ABB Switzerland Ltd., Switzerland
}

\begin{abstract}
In this paper a thermosyphon design for power electronics cooling is presented and supported by an extensive experimental campaign. The work tackles the problem of finding a suitable substitute of common air cooled heat sinks towards a highly thermally performing device overcoming the bottleneck of limited fin efficiency and proposing a device with reduced air pressure drop. The basic thermal circuit is based on a two-phase thermosyphon system. The evaporator channels are such that the so-called bubble-pumping effect is present, facilitating the natural movement of the fluid in the device. The degree of novelty is introduced by the usage of a condenser made of roll-bonded panels. A common double-sided evaporator body collects the heat generated by two power modules. The employed fluid is refrigerant R245fa. The paper presents the thermal performance of the described two-phase cooler in a forced convection regime (air side). The experimental campaign covers total power losses ranging from 1 to $4 \mathrm{~kW}$ and different air mass flow rates. The paper presents and demonstrates an attractive cooling solution for power electronics modules based on a two-phase cooler.

Keywords: electronics, cooling, thermosyphon, two-phase, condenser, forced convection, roll-bond.
\end{abstract}

\section{Introduction}

Research toward efficient cooling systems of power electronics devices represent a challenge and an important target in many electronic applications. In this direction pumpless two-phase cooling devices, so-called thermosyphons, represent an important benefit for the thermal management. 
Thermosyphons are well known in the thermal community, but the high flexibility and freedom in the design of these devices leaves a lot of unknowns and questions to be answered that require a strong effort from the researcher. Past studies include the thermal management of IGBT modules employing twophase thermosyphons can be found in Perpiñà et al. [1], focusing on the thermal cycling and the effect of the cooling media on the performances as in Palm and Khodabendeh [2].

Usage of small-diameter thermosyphons appears to be beneficial. Literature is available, but only limited experimental data are covering this topic. However, available studies are beneficial to outline some general trends. Critical heat flux (CHF) is an important physical limit of two-phase flows. Islam et al. [3] target the optimization of tube diameters to maximize the CHF. Mukherjee and Mudawar [4,5] studied the geometry of a micro-channel boiler with the aim of maximizing the CHF compared to pool boiling conditions. Another issue in such systems are flow instabilities. Nayak et al. [6] studied this phenomena in reactor thermosyphons, focusing on the effect of diameter, vapor qualities, subcooling and riser length. Coming to operation conditions, the filling ratio is an important variable on which the designer can act to maximize the performance of the system. In this direction several studies for different conditions are available. For example Ong and Haider-E-Alahi [7] investigated this effect on an R134a-filled thermosyphon, showing a maximum performance at 0.8. Abou-Ziyan et al. [8] found a maximal performance at a filling ratio of 0.5. MacDonald et al. [9] measured experimentally an optimum at $35 \%$ filling ratio with refrigerant R11 in a large-diameter tube. These substantial difference can be explained as highlighted by Ong and Haider-E-Alahi [7] and Abou-Ziyan et al. [8], that, having different evaporator, riser and condenser lengths, found different optimal filling ratios. The performances of two-phase thermosyphon loops with small-diameter evaporator channels have been recently measured by Khodabandeh $[10,11]$. The evaporatorchannel diameter ranged from 1.1 to $3.5 \mathrm{~mm}$, but the riser had a diameter of $6.1 \mathrm{~mm}$. The heat transfer coefficient was found to be strongly dependent on the heat flux, and the pressure drop had to be adequately predicted by the homogeneous model.

In this paper we extend the work presented by Agostini et al. [12], originally investigating the natural convection performance of a two-phase thermosyphon. Our focus is now in presenting a wide experimental campaign covering forced air convection conditions and demonstration the operation of the device over a wide range of conditions.

\section{Description of the cooling loop}

In this section we provide a detailed description of the cooling loop: thermosyphon, condenser, connecting tubing and evaporator body. 


\subsection{Two-phase thermosyphon}

The presented system is a gravity-driven two-phase thermosyphon for power electronics cooling. It comprises an evaporator, a vapor riser, a condenser from roll-bonded panels, and a liquid return. The presented design can cool 2 multichip IGBT modules of footprint 140 by $190 \mathrm{~mm}$. For the present study, ABB HiPak modules, $6500 \mathrm{~V}$ and $600 \mathrm{~A}$ were chosen.

It is important to note that this system is scalable, and the present experimental setup is only an example. For instance, the width of the evaporator could be doubled or tripled to allow for the mounting of 4 or 6 power modules. Along with evaporator, the width of the condenser stack could be increased to keep the air-flow rate per cooling power constant at constant air speed.

Further possible modifications pertain to the dimensions of the condenser panels and their total number, and to the vertical distance between evaporator and condenser. These dimensions can be adapted as needed for the specific application at hand. It is clear that an increased vertical distance between the evaporator and condenser is beneficial for thermosyphon performance.

The system is depicted in Fig. 1.

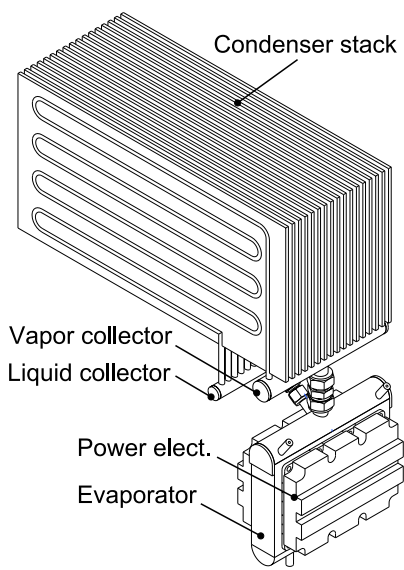

Figure 1: Thermosyphon assembly [12].

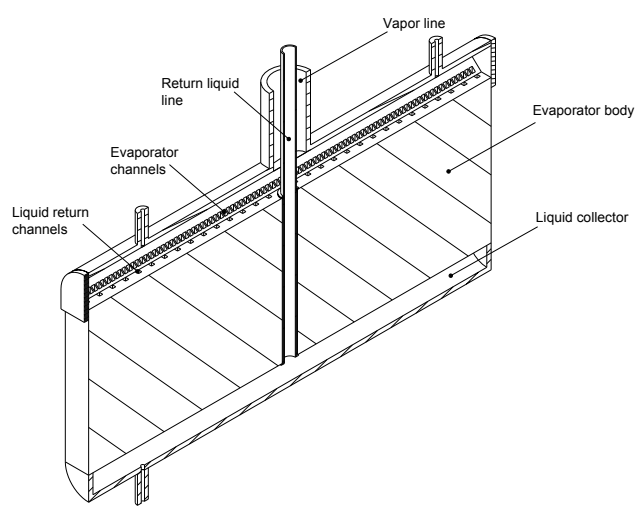

Figure 2: Evaporator cross section [13].

\subsection{Evaporator body}

The evaporator body is a brazed aluminum block. The main components are:

- Bottom liquid collector: It is a pool of liquid constantly feeding the evaporator channels.

- Central body: It contains the central liquid return channel that feeds the bottom liquid collector, the evaporator channels and the liquid return 
channels. It further contains the threaded bores for attachment of the power modules. The central body is both left/right- and front/back-symmetric, and allows for the attachment of a power module of footprint $140 \mathrm{~mm}$ by $190 \mathrm{~mm}$ on both front and back side. The evaporator channels have a pitch of $5 \mathrm{~mm}$ and a hydraulic diameter of $3 \mathrm{~mm}$ that facilitates the bubble-pumping effect.

- Top collector: It receives the vapor/liquid mixture from the evaporator channels, and allows for separation of the liquid from the vapor by discharging the vapor to the vapor riser, while the liquid returns downwards to the liquid-return channels and into the bottom liquid collector.

For more details on the evaporator design, the reader is referred to [13].

A cross section of the evaporator body is provided in Fig. 2.

The current evaporator, with two series of channels, guarantees an unique design allowing a natural separation of the liquid phase from the vapor phase. Generically the discharge at the top of the evaporator is such that the vapor quality is much below 1 to guarantee a safe operation of the device and to keep the working conditions far away from the so called critical heat flux conditions. This operating consideration imposes a mixture of vapor and liquid an the entrance of the condenser that if avoided can reduce the probability of miss-operation of the

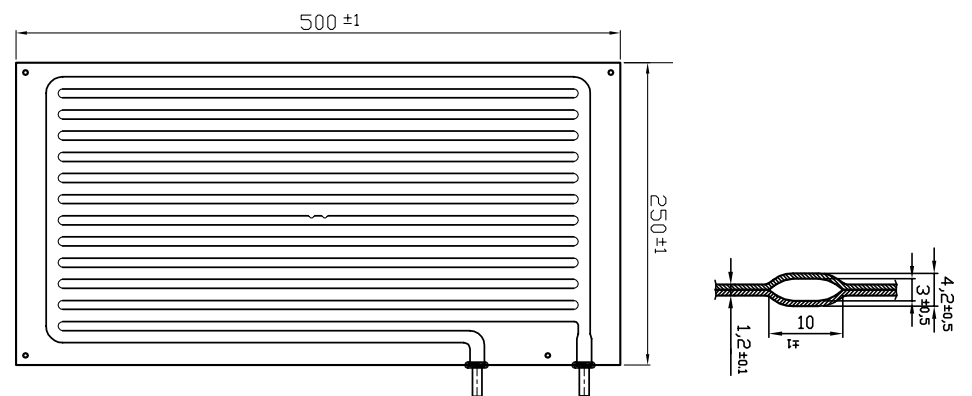

Figure 3: Condenser panel geometry [12].

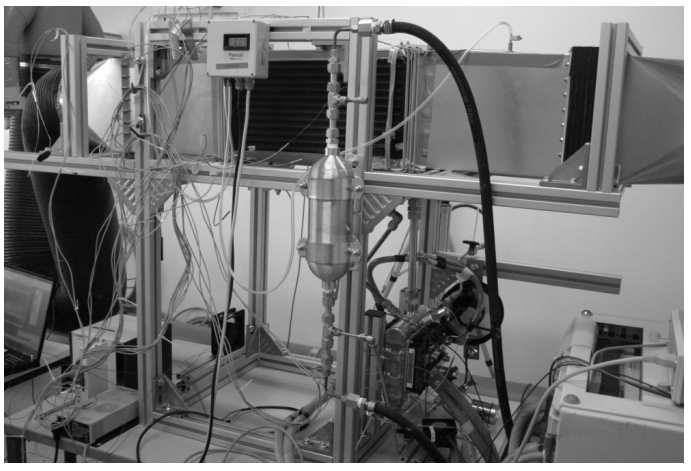

Figure 4: Experimental set-up, laboratory installation. 
system. In our specific case this is achieved by means of a double channel structure. The hydraulic diameter of the cooling channels is $D_{\mathrm{h}}=3 \mathrm{~mm}$ with a pitch $p=$ $5 \mathrm{~mm}$; these dimension guarantee the so called pumping effect in thermosyphon operation conditions.

The return liquid main channel line is built in such a way that a metallic ring is the only contact between the hose and the evaporator body. This configuration allows a limited contact reducing the heat exchange between the liquid stream and the body of the evaporator. If required, this contact can be allowed and the return hose being directly in contact/part of the evaporator body.

The coaxiality of the liquid return is not mandatory; from a construction point of view the central body can be extruded and the top and bottom manifolds afterward welded on it.

\subsection{Vapor line and main liquid return}

The vapor line connects the top of the evaporator body with the inlet of the condenser. It consist of a vertical tube centrally attached to the evaporator, and a manifold, from which tubes branch out to the individual panels. The internal diameters are $16 \mathrm{~mm}$ for the central vertical pipe, $19 \mathrm{~mm}$ for the manifold, and $8 \mathrm{~mm}$ for the panel-supply pipes.

The liquid return is built up similarly, with panel-connector pipes of $8 \mathrm{~mm}$ internal diameter and a collector manifold of $16 \mathrm{~mm}$ internal diameter. From this manifold, an inclined, central liquid-return pipe of $10 \mathrm{~mm}$ internal diameter leads back to the evaporator.

All the pipework is made from aluminum. The connections between panels, panel-supply pipes, manifolds and central pipes are welded, while stainless-steel connections are used for coupling with the evaporator, see Fig. 1.

\subsection{Condenser}

The condenser consists of a stack of 13 aluminum panels with a panel-to-panel pitch of $18 \mathrm{~mm}$. Each panel is $1.2 \mathrm{~mm}$ thick, $500 \mathrm{~mm}$ long (in air-flow direction) and $250 \mathrm{~mm}$ high. As described in [13], each panel contains 11 horizontal flow channels of a nominal length of $390 \mathrm{~mm}$. The panels are double sided, which means that each flow channel is present on both sides with a trapezoid cross section.

\subsection{Fluid}

The working fluid used is pentafluoropropane R245fa. The fluid shows good thermal characteristics and a relatively low saturation pressure over the investigated temperature range. 


\section{Experimental set-up}

The experimental test set-up is depicted in Fig. 5: Two power modules are attached back-to-back to a common evaporator body. The evaporator top collector drives the vapor flow towards a distributor that equally feeds the stack of condenser panels. Once the vapor condensates, the liquid phase is driven by gravity into a liquid manifold and drained to the bottom of the evaporator as in the system investigated in [13] and [12].

The condenser is cooled by forced air.

During operation the heat generated by the power modules is collected by an evaporating fluid. The generated vapor travels towards the condenser by gravity and the forced air stream removes the collected heat, allowing condensation of the vapor.

The thermosyphon loop on the refrigerant side is monitored by means of thermocouples placed in the circuit. A first thermocouple is placed in the liquid bottom collector, giving an indication of the inlet evaporator temperature. At the same location an absolute measure of pressure is present, from this measure the saturation temperature conditions are monitored. A second measure of temperature takes place at the evaporator discharge. The temperatures measured at these twophase loop locations allow to monitor and detect the possible presence of subcooling and super-heating. In the evaporator body four thermocouples monitor the temperature $1 \mathrm{~mm}$ below the evaporator surface, providing a detailed picture of the base temperature. The maximum base temperature is used to evaluate the maximum junction temperature.

To monitor the condenser, six thermocouples are attached to an outer wall of the central panel. This yields information on the spatial distribution of the panel material. On the air side, the mass-flow rate is monitored with a massflow meter. One thermocouple provides the air temperature at the inlet of the condensing section, while five thermocouples are distributed over the channel cross-section to measure the air temperature downstream the condenser. The airtemperature increase over the condenser panels is an important reference value for the calculation of the thermal balance. The air-pressure drop is monitored my means of a differential pressure transducer.

In the air flow loop an air blower drives an air stream in the wind tunnel test rig, the operating conditions are controlled by means of a variable-speed drive. Following the air stream we encounter the air-flow meter and a pre-heating section. At this location the air temperature is regulated to the required conditions. The pre-heated air stream then encounters a stack of 5 wire meshes to have a uniform velocity distribution and a low turbulence intensity at the test-section entrance. At this location the heat is collected by the air stream and removed from the two-phase cooling loop. At the discharge of the test section the air stream is driven through a heat exchanger connected to a chilling unit to decrease the air temperature prior to entering the blowing unit. This last component is required, since the loop is a closed-loop wind tunnel. 


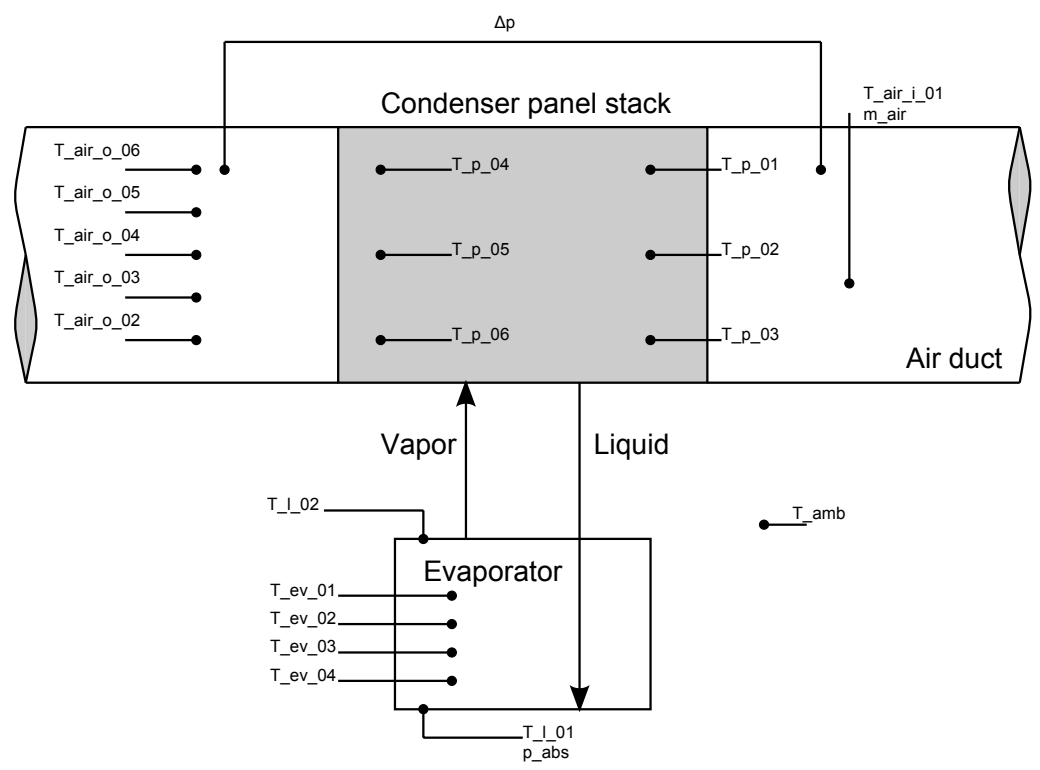

Figure 5: Measurement locations, overview.

\subsection{Measurement devices and accuracies}

Thermocouples of type $\mathrm{K}$ of diameter $1 \mathrm{~mm}$ were employed. When installed in a bore, the bore diameter was $1.2 \mathrm{~mm}$, and the bore was filled with thermally conductive paste of thermal conductivity of $3 \mathrm{~W} /(\mathrm{m} \mathrm{K})$. Following the same approach, and to have controlled experimental conditions, thermal paste was also used to couple the power modules to the evaporator: An approximately $0.10 \mathrm{~mm}$ thick layer of paste was evenly distributed, the thermal conductivity of the paste being $0.8 \mathrm{~W} /(\mathrm{m} \mathrm{K})$. A summary of the measuring devices and accuracy is given in Table 1.

With $T_{\text {air,in }}$ being the inlet air temperature, $T_{\text {base }}$ the maximum base temperature measured in evaporator side and $Q$ the total power dissipated, the total thermal resistance was calculated with the following formula:

$$
R_{\mathrm{th}(\mathrm{b}-\mathrm{a})}=\frac{T_{\mathrm{base}}-T_{\mathrm{air}, \mathrm{in}}}{Q} .
$$

The uncertainty on the thermal resistance was calculated with

$$
\frac{\Delta R_{\mathrm{th}(\mathrm{b}-\mathrm{a})}}{R_{\mathrm{th}(\mathrm{b}-\mathrm{a})}}<\frac{\Delta Q}{Q}+\frac{\Delta T_{\text {air }, \text { in }}+\Delta T_{\text {base }}}{T_{\text {base }}-T_{\text {air }, \text { in }}},
$$

yielding a maximum uncertainty between $\pm 10.8 \%$ and $\pm 7.2 \%$ at the highest $(4000 \mathrm{~W})$ and lowest thermal loads $(1000 \mathrm{~W})$, respectively. In this calculation the uncertainty on the power accounts for the thermal balance over the test section. 
Table 1: Measuring devices and accuracy.

\begin{tabular}{|l|l|l|l|}
\hline Measurement device & Range & Accuracy & Unit \\
\hline \hline TC type K & $10-100$ & \pm 0.1 & $\left({ }^{\circ} \mathrm{C}\right)$ \\
\hline Power supply XDC 10-1200 & $\begin{array}{l}0-10 \\
0-1200\end{array}$ & $\begin{array}{l} \pm 0.015 \\
\pm 6\end{array}$ & $\begin{array}{l}(\mathrm{V}) \\
(\mathrm{A})\end{array}$ \\
\hline $\begin{array}{l}\text { Absolute pressure transducer } \\
\text { ABB 261 AS }\end{array}$ & $0-3000$ & \pm 1 & $(\mathrm{kPa})$ \\
\hline $\begin{array}{l}\text { Mass flow meter ABB Sen- } \\
\text { syflow D }\end{array}$ & $0-1000$ & $\pm 2 \%$ & $\left(\mathrm{~m}^{3} / \mathrm{h}\right)$ \\
\hline
\end{tabular}

Table 2: Measurement points.

\begin{tabular}{|l|l|l|}
\hline Probe ID & Media & Description \\
\hline \hline T_amb & Air & Ambient temperature \\
\hline T_air_i_01 & Air & $\begin{array}{l}\text { Air temperature upstream condenser } \\
\text { stack }\end{array}$ \\
\hline T_air_o_02-06 & Air & $\begin{array}{l}\text { Air temperature downstream condenser } \\
\text { stack }\end{array}$ \\
\hline$\Delta p$ & Air & Air pressure drop \\
\hline T_ev_01-04 & Aluminum & Evaporator body temperature \\
\hline T_p_01-06 & Aluminum & Condenser wall temperature \\
\hline T_1_01-02 & Refrigerant & $\begin{array}{l}\text { Refrigerant loop temperature, in/out } \\
\text { evaporator }\end{array}$ \\
\hline p_abs & Refrigerant & Refrigerant loop absolute pressure \\
\hline
\end{tabular}

\section{Experimental results}

In Tab. 3 the experimental conditions are summarized.

In Fig. 6 the thermal resistance $R_{\mathrm{th}(\mathrm{b}-\mathrm{a})}$, calculated according to Eq. 1 is depicted as a function of the thermal load. Tests were run for different mass flow rates ranging from $1400 \mathrm{~kg} / \mathrm{h}$ to $3000 \mathrm{~kg} / \mathrm{h}$. Under these conditions the total thermal resistance ranges from 13 to $18 \mathrm{~K} / \mathrm{kW}$ for the lower mass flow rate and from 10 to $15 \mathrm{~K} / \mathrm{kW}$ for the highest flow rate. Taking a closer look at the total thermal resistance, the contribution of the individual terms gives an important highlight 
Table 3: Experimental conditions.

\begin{tabular}{|l|l|}
\hline Fluid & $245 \mathrm{fa}$ \\
\hline Refrigerant charge & $2 \mathrm{~kg}$ \\
\hline Filling Ratio & 0.5 \\
\hline Heat load & $1.0-4.0 \mathrm{~kW}$ \\
\hline Condenser air inlet temperature & $25^{\circ} \mathrm{C}$ \\
\hline Air mass flow rate & $1400-3000 \mathrm{~kg} / \mathrm{s}$ \\
\hline
\end{tabular}

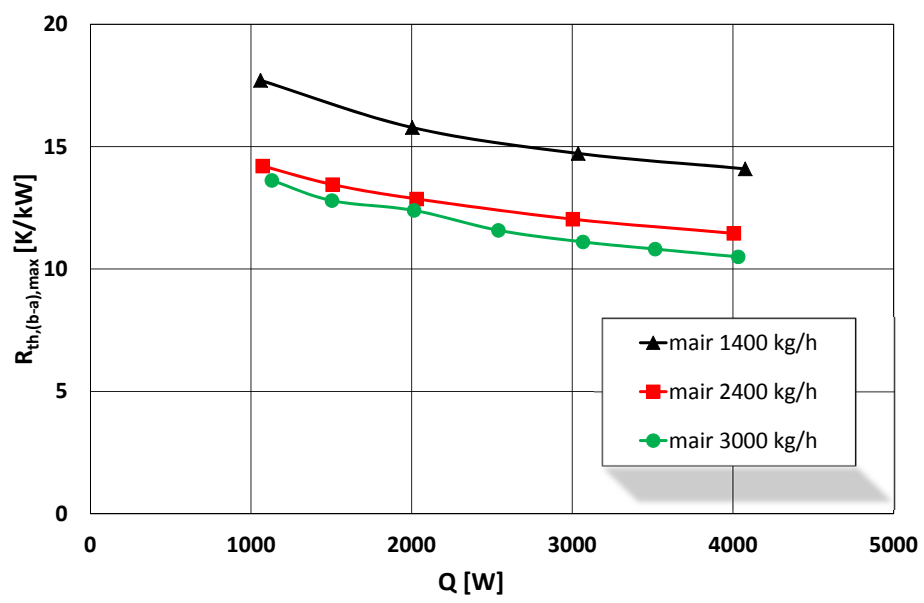

Figure 6: Thermal resistance $R_{\mathrm{th}(\mathrm{b}-\mathrm{a})}$.

about the thermal performances. In Fig. 7 the contribution of the individual terms is given: The total thermal resistance is split into the condenser, evaporator and base components for an air flow rate of $2400 \mathrm{~kg} / \mathrm{h}$. The condenser thermal resistance is calculated from the temperature difference between the saturation and air inlet temperature. This thermal resistance is constant over the investigated power range. Since the base temperature is a good approximation of the cooler surface, a surface temperature of the evaporator channels can be computed, considering the metal wall thickness and accounting for the thermal conduction through the baseplate. From this value, the evaporator thermal resistance can be calculated and shows a decreasing trend with increasing total power. As last curve plotted, the base thermal resistance represents the conduction through the baseplate thickness and is constant. In Fig. 8, the maximum junction temperature, calculated using the thermal resistance from junction to heat-sink base $R_{\mathrm{th}(\mathrm{j}-\mathrm{b})}$, is plotted as a function of the total power and for three different mass flow rates. For the lowest flow rate of $1400 \mathrm{~kg} / \mathrm{h}$, the junction temperature ranges from $52{ }^{\circ} \mathrm{C}$ to $1000 \mathrm{~W}$, and 
216 Advanced Computational Methods and Experiments in Heat Transfer XII

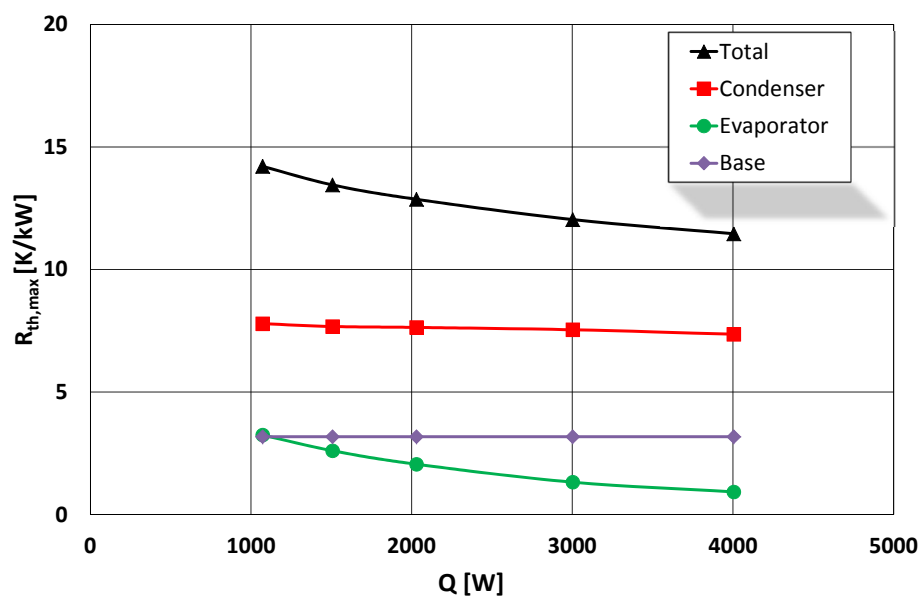

Figure 7: Thermal-resistance breakdown, $\dot{m}_{\text {air }}=2400 \mathrm{~kg} / \mathrm{h}$.

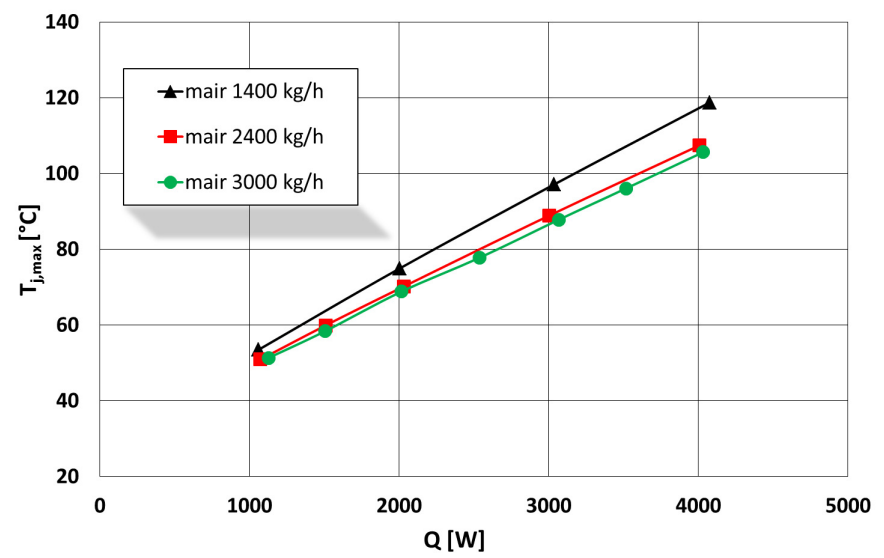

Figure 8: Maximum junction temperature, calculated from $T_{\mathrm{b}, \max }$.

reaches $120{ }^{\circ} \mathrm{C}$ for $4000 \mathrm{~W}$ losses. Following the same approach previously presented and with focus on the case of $2400 \mathrm{~kg} / \mathrm{h}$ air-flow rate, in Fig. 9 a plot of the saturation, base and junction temperatures are given for different cooling powers. The comparison of the different temperature gives a good indication of the temperature levels, highlighting the contribution of the individual thermal resistances on the thermal load of the device.

In Fig. 10, the saturation temperature is plotted for different flow rates over the investigated power range. The saturation temperature increase almost linearly with the power.

Additionally to traditional temperature measurements by means of thermocouples, an exterior panel of the condenser stack was painted black and monitored by 


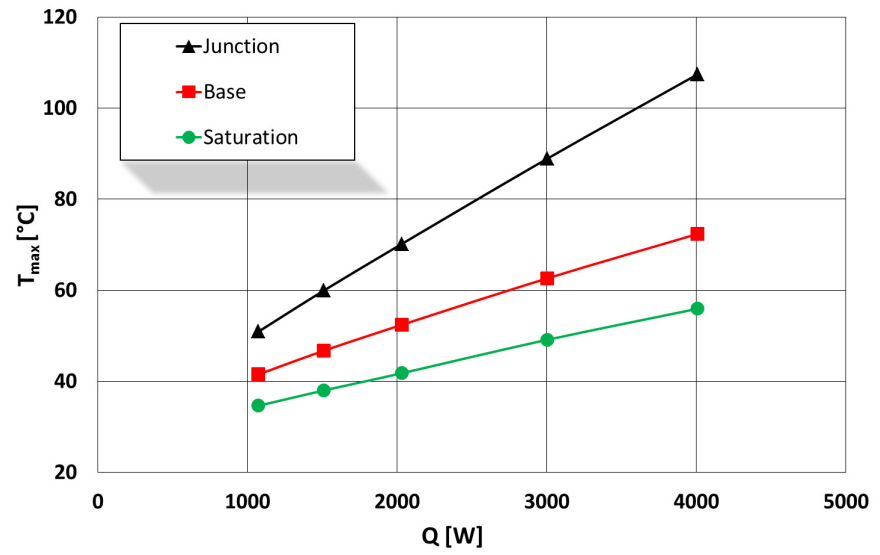

Figure 9: System temperatures, $\dot{m}_{\text {air }}=2400 \mathrm{~kg} / \mathrm{h}$.

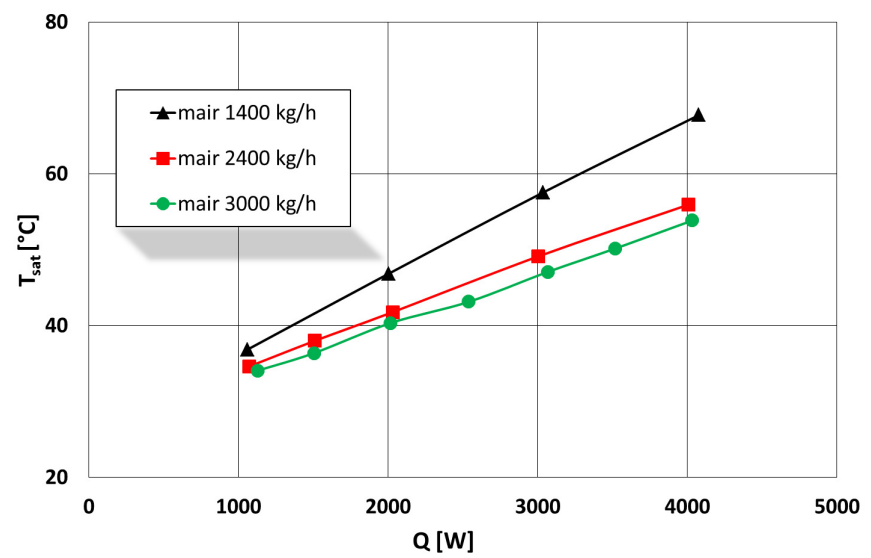

Figure 10: Saturation temperature.

an infrared camera. Fig. 11 shows an example (air flow right to left). The qualitative distribution is typical for most of the operating conditions tested. A hot spot is clearly visible, located around the vapor-riser channel, extending downstream somewhat in the upper half of the panel. The temperature difference between this hot spot and most of the cooler part of the panel is about $10{ }^{\circ} \mathrm{C}$. Since the fluid pressure variations are small and the bulk fluid is close to two-phase equilibrium, such temperature variations cannot be explained by variation of the bulk fluid temperature. It is therefore expected that high panel temperatures result from high values of the heat-transfer coefficient $h_{\mathrm{f}-\mathrm{p}}$ from bulk fluid to channel wall. A high value of $h_{\mathrm{f}-\mathrm{p}}$, in turn, is an indication of high fluid velocity. This suggests that most of the vapor passes through the upper half of the panel. Physically, such a behavior makes sense, as it is easiest for the vapor rising in the vertical channel to 


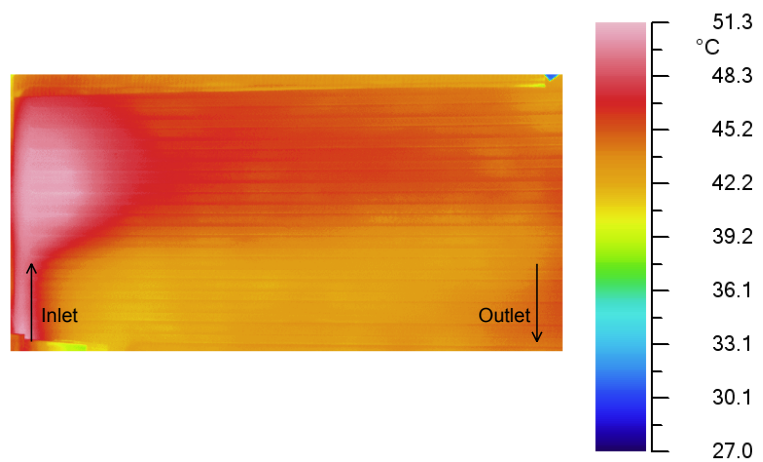

Figure 11: Example of infra-red measurement: $\dot{m}_{\text {air }}=2400 \mathrm{~kg} / \mathrm{h}, \mathrm{Q}=4000 \mathrm{~W}$.

go straight ahead instead of branching out to the lower horizontal channels. This is because in a $90^{\circ} \mathrm{T}$-junction, the pressure drop for the fluid going straight is lower than for the fluid branching off. On top of that, there might be a liquid column extending to a certain height in the vertical liquid collector channel of the panel. The hydrostatic pressure in this column counteracts the flow through the lower horizontal condenser channels.

Another feature observed is that within the upper half of the panel, the panel temperature decreases from left to right, i.e. along the condenser channel in fluidflow direction. This is explained by the fact that, as condensation progresses, the mean fluid density and hence the velocity decreases, which lowers $h_{\mathrm{f}-\mathrm{p}}$ and hence the panel temperature.

It is noted that this exterior panel, for which the infrared measurements were made, is not fully representative, since, unlike the interior panels, it is subject to forced convection only on the inner side. On the outer side, the heat transfer is comparatively low, with contributions from natural convection and radiation.

Starting from the geometry presently investigated, an optimization of the condenser channels is conceivable, e.g. enlarging the lower part of the vapor-riser channel, leading to a more uniform distribution of fluid flow through the horizontal channels, and hence to a more efficient overall usage of the panel area.

\section{Conclusion}

In the present paper a two-phase thermosyphon cooler for power electronic devices was presented. The operation covered forced air convection with mass flow rates ranging between 1400 to $3000 \mathrm{~kg} / \mathrm{h}$. The total thermal resistance attained values between 10 and $18 \mathrm{~K} / \mathrm{kW}$ over a range of power losses of 1 to $4 \mathrm{~kW}$.

The presented experimental results integrate and extend a wide study covering the usage of roll-bond type condensers. The study shows the potential of two-phase flow in the domain of electronic cooling highlighting the high efficiency transfer of heat from the source where is dissipated up to final cooling media. If the global working principal of the thermosyphon is well defined and understood, work still 
need to be done to fully master the design and the understanding of roll bond condensers.

\section{References}

[1] Perpiñà, X., Piton, M., Mermet-Guyennet, M., Jordà, X. \& Millán, M., Local thermal cycles determination in thermosyphon-cooled traction igbt modules reproducing mission profiles. Microelectronics Reliablity, 47(9-11), pp. 1701-1706, 2007.

[2] Palm, B. \& Khodabandeh, R., Choosing working fluid for two-phase thermosyphon systems for cooling of electronics. Journal of Electronic Packaging, 125, pp. 276-281, 2003.

[3] Islam, M.A., Monde, M. \& Mitsutake, Y., CHF characteristics and correlations of concentric-tube open thermosyphon working with R22. International Journal of Heat and Mass Transfer, 48, pp. 4615-4622, 2005.

[4] Mukherjee, S. \& Mudawar, I., Pumpless loop for narrow channel and microchannel boiling. Journal of Electronic Packaging, 125, pp. 431-441, 2003.

[5] Mukherjee, S. \& Mudawar, I., Smart pumpless loop for micro-channel electronic cooling using flat and enhanced surfaces. IEEE Transactions on Components and Packaging Technologies, 26(1), pp. 99-109, 2003.

[6] Nayak, A., Lathouwers, D., van der Hagen, T., Schrauwen, F., Molenaar, P. \& Rogers, A., A numerical study of boiling flow instability of a reactor thermosyphon system. Applied Thermal Engineering, 26, pp. 644-653, 2006.

[7] Ong, K. \& Haider-E-Alahi, M., Performance of a R-134-a-filled thermosyphon. Applied Thermal Engineering, 23, pp. 2373-2381, 2003.

[8] Abou-Ziyan, H., Helali, A., Fatouh, M. \& El-Nasr, M.A., Performance of stationary and vibrated thermosyphon working with water and R134a. Applied Thermal Engineering, 21, pp. 813-830, 2001.

[9] MacDonald, T., Hwang, K. \& Diciccio, R., Thermosyphon loop performance characteristics: Part 1. Experimental study. ASHRAE Trans, 83(2467), pp. 250-259, 1997.

[10] Khodabandeh, R., Heat transfer in the evaporator of an advanced two-phase thermosyphon loop. International Journal of Refrigeration, 28, pp. 190-202, 2005.

[11] Khodabandeh, R., Pressure drop in riser and evaporator of an advanced twophase thermosyphon loop. International Journal of Refrigeration, 28, pp. 725-734, 2005.

[12] Agostini, F., Gradinger, T. \& de Falco, C., Simulation aided design of a twophase thermosyphon for power electronics cooling. Proceedings of IECON 2011 - 37th Annual Conference of the IEEE Industrial Electronics Society, Melbourne, Australia, 2011.

[13] Agostini, F. \& Agostini, B., Flexible two-phase thermosyphon for power electronic cooling. Proceedings of the 33rd International Telecommunications Energy Conference, INTELEC 2011, Amsterdam, The Netherlands, 2011. 